\title{
Methods of Delivery of Lectures in the Classroom
}

\author{
Munmun Shabnam Bipasha \\ Lecturer of Economics, Daffodil International University Dhaka, Bangladesh
}

\begin{abstract}
Tertiary education usually indicates higher education particular to undergraduate and graduate programs of study, which comes after elementary and high school completion. After the enactment of the Private University Act in 1992, the private universities in Bangladesh recorded a phenomenal growth. Both the sectors are providing a higher education and making a competitive environment. But in practice, some private universities are very weak and some questions are here about the quality of education. May be those universities are using all modern training aids but are the students benefiting?

We know prime aim of a teacher is to make his/her listeners understand and for that a flow of communication between these two agents is very vital. A teacher has to be very likely with the capability of making other's understand. On the other hand, listeners have to be responsive. Earlier chalk, black-board etc. were used by the teachers as a training aid. But with the advancement of science and technology, slide projectors came into play, after that overhead projectors and now we are in the age of multimedia projectors. But the question remains about the effectiveness of these advance technologies. Are these advance technologies making students more responsive or making a scope for them to remain silent?
\end{abstract}

Key Words: Higher Education, History, Few Recommended methods, Present Experience, Solution.

\section{Introduction}

Bangladesh is a small country but her prospect in terms of economic, social or education is very remarkable. There is a close relationship between the level of economic production and the spread of higher education. Education is a backbone of a nation. To make this backbone strong, government should concentrate on the education system, especially on the tertiary education because it is the last stage of education. The success of tertiary education depends largely on the teaching-learning methodology in the classroom. The students are the future leaders and assets of a country. So they should be trained and developed to face the growing challenges in near future. But unfortunately a good number of students in Bangladesh do not receive university education due to various causes like poverty, unawareness about the importance of education or no scope. So we should try to open the doors of higher education for more and more students without compromising the quality. To ensure education quality, teachers must find out the useful, effective and best teaching methods when they delivery lectures in the classroom. ? I carried out a survey recently in different issues on present education system which shows that $85 \%$ students support the use of modern technologies in class room. Details of the survey reports are highlighted in this paper. This paper also depicts to describe the present method of delivery lecture in the classroom using modern technology and also describes two teachinglearning methods which are likely to make the process more effective.

\section{Reasons Behind Teaching-Learning Methodology Of Bangladesh}

At present, the current tertiary teaching-learning methodology of Bangladesh is similar to the times of British India. In 1835, the chairman of Education Committee of East India Company, Thomas Rabington Mackle said 'the object is to create a class of people Indian in blood and color but English in taste, in opinions, in mind and in intellect'. This essentially meant that the British developed a system of higher education in colonial India that basically created only "clerks". Their skill revolved around records and accounts keeping and drafting of documents. The education policy of East-India Company was to create a class of 'loyal servants' to work in office of the British rulers. Creativity and independent thinking were not required for those 'loyal servants'.

Through history, Bangladesh has gone through various phases of education systems. From the time of the English rule to Pakistan regime and finally Bangladeshi system, education has evolved not only in methods but also in fundamental aspects like language and governance. After the liberation war of Bangladesh in 1971, our country became an independent nation and frees to choose its own education destiny. As Bangladesh was and still is, a secular state, many forms of education were permitted to co-exist. The formidable British system was and still is largely practiced. Independence has had little or no positive effect on changing the basic education delivery methodology and teaching-learning methodology translate into day-to-day classroom teaching. Actually, in 12 years of primary and secondary education system, the education delivery culture forces 
the children to memorize and provides resources to help them memorize and after 12 years, these students are eligible for tertiary or university education.

At present there are 34 public and 54 private universities in Bangladesh (Source: UGC, Bangladesh). On average, 65 students apply for each seat at a public university. Realizing that a large number of students were being deprived of higher education, the government has rightly provided a legal framework commonly referred to as the Private University Act (PUA) of 1992. The modern world of science and technology which public universities could not provide due to fund constraints, the private universities could provide the fund and offer courses which are guided by the market related phenomena. The private higher education institutions can reduce the financial burden of government and can help maintain academic schedules and also avoid session jams. Education results, attendance, class participation and evaluation of students are ensured and monitored properly. The quality of higher education now is a global issue. Not only are developing countries, developed countries also concern about this. For this reason, the teachers must know the actual methods of delivering lectures in the classrooms. President Barak Obama said: 'We know a good teacher can increase the lifetime income of a classroom. A great teacher can offer an escape from poverty the child who dreams beyond his circumstances. Most teachers work tirelessly, with modest pay'.

The success of tertiary education mostly depends on teachers. It also depends on how a teacher deliveries lecture in a classroom. In Bangladesh, university education is likely to be adversely affected by its poor base line i.e. intake. Quality of primary and secondary level is not satisfactory in most cases. Thus the outputs provide as inputs of universities are found to have adversely affected quality of graduates in line with 'low level trap' (UGC 2005).

In Bangladesh, the present method of teaching and learning in both public and private universities is not very effective. The growth of quality of education in all levels is based on teaching method to a greater extent which needs to be supported with required infrastructure and facilities. Such a situation is very much lacking which needs to be upgraded. In public university, the higher education is highly subsidized. There has been commensurate expansion of faculty in universities. Enrollment rate has increased over periods. But the expansion is mostly quantitative. The quality of education has not improved. Even in most of the public universities, teachers do not want to use modern technology when they delivery lectures in the classroom. From my recent survey, $85 \%$ students prefer technology while delivering lecture by a teacher in the classroom and $99 \%$ student think that internet use is necessary in present education system.

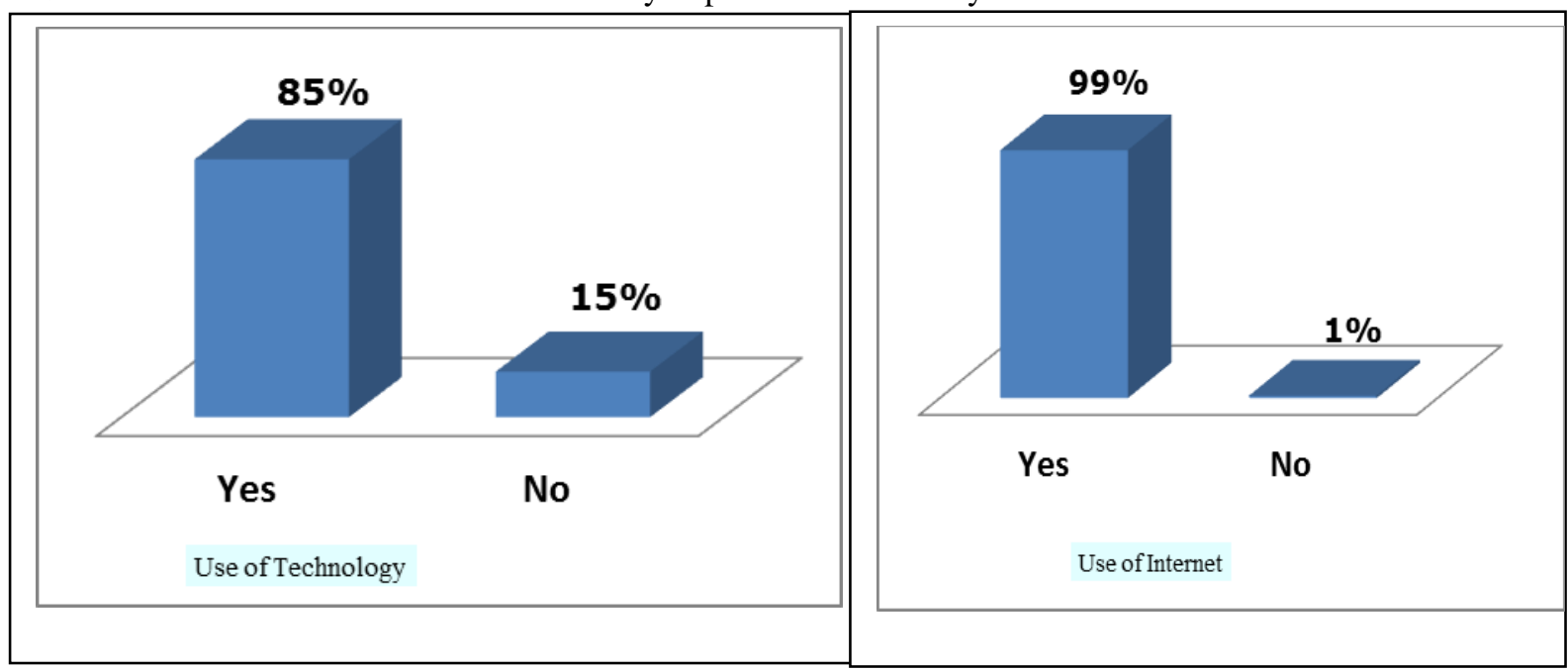

It is very unfortunate that the present government slogans that to make digital Bangladesh, but many teachers specially in arts and humanities department in public university do not have any interest to use technology in the classroom, even many of them do not know how to use modern technology while delivering lectures in the classroom. In public universities, some teachers remain very busy with politics. For this reason, they do not take classes in time, even some of them do not have any concern about the syllabus or course outline.

On the other hand, in private university a good number of teachers use technology in the classroom. But most of the teachers in private university complain that a huge number of students do not read and cannot write even a sentence of English correctly and they have little or no idea of sentence construction. All the private universities claim that their medium of instruction is English. So, if many students of a class do not have proper knowledge about English language, then the teachers face difficulties to delivery lecture in English. Moreover, in university, many students ask teacher about note. They don't want to read books. Most of them are trying to find out the short cut processes. From the survey, I find that after delivering lectures, 26\% students 
want book as a reference, $44 \%$ of them want hand-notes made by the teachers and $30 \%$ want lecture sheets. Only a few numbers of students are self-learners or like to create their own notes. It is a matter of sorrow that some teachers also delivery hand-notes to the students after finishing the class. Even these teachers sometimes do not give marks if they do not find word for word match of hand notes in students' exam-sheets.

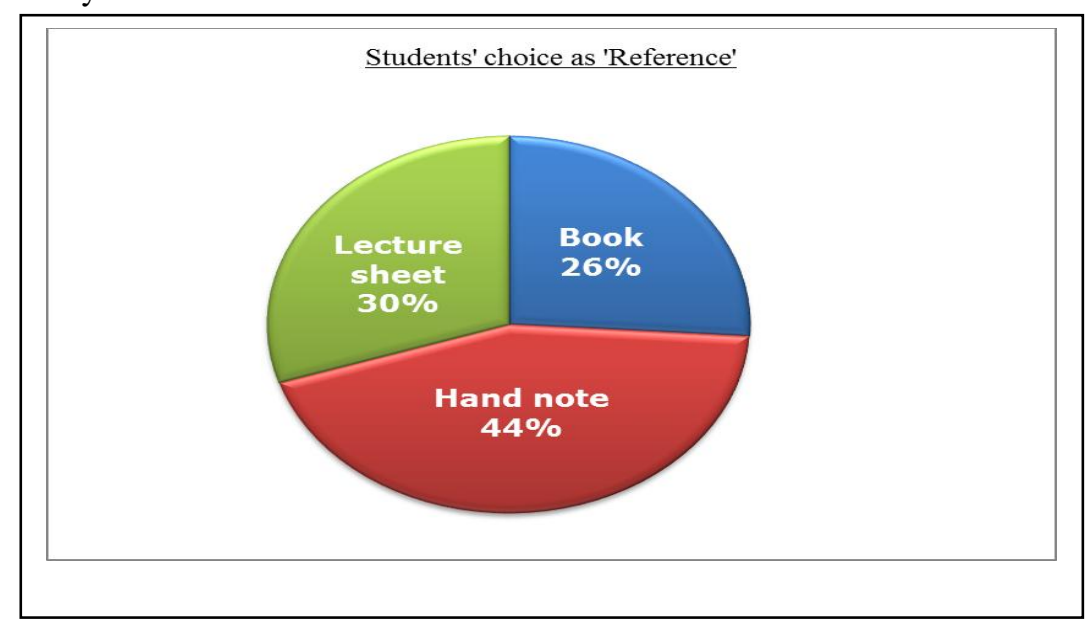

The success of teaching depends on how teachers' delivery lectures and influence students to do research work. Private universities are blamed for not doing adequate research work as it is mandatory for a university. Due to the shortage of fund and lack of positive support from the concern authorities, the research works are avoided at times even in public universities.

\section{Few Recommended Teaching Methods For Bangladesh}

A good teaching means an instruction that leads to effective learning, which in turn means thorough and lasting acquisition of the knowledge, skills, and values the instructor or the institution, has set out to impart. In this paper, I want to describe several methods known to be particularly effective and teachers can usually use any of these in the classroom.

Most students cannot stay focused throughout a lecture. After about 10 minutes their attention begins to drift, first for brief moments and then for longer intervals, and by the end of the lecture they are taking very little and retaining less. A classroom research study showed that immediately after lecture students recalled $70 \%$ of the information presented in the first ten minutes and only $20 \%$ of that from the last ten minutes (McKeachie 1999).

I carried out a survey recently amongst the students of different back ground where it is found that the students prefer using modern technologies in the class room. They were told to make a list of training aids (Multimedia projector, overhead projector, white board-marker and black board-chalk) according to the priority and multimedia projector was student's first choice. Detail survey result is given below as bar diagram.

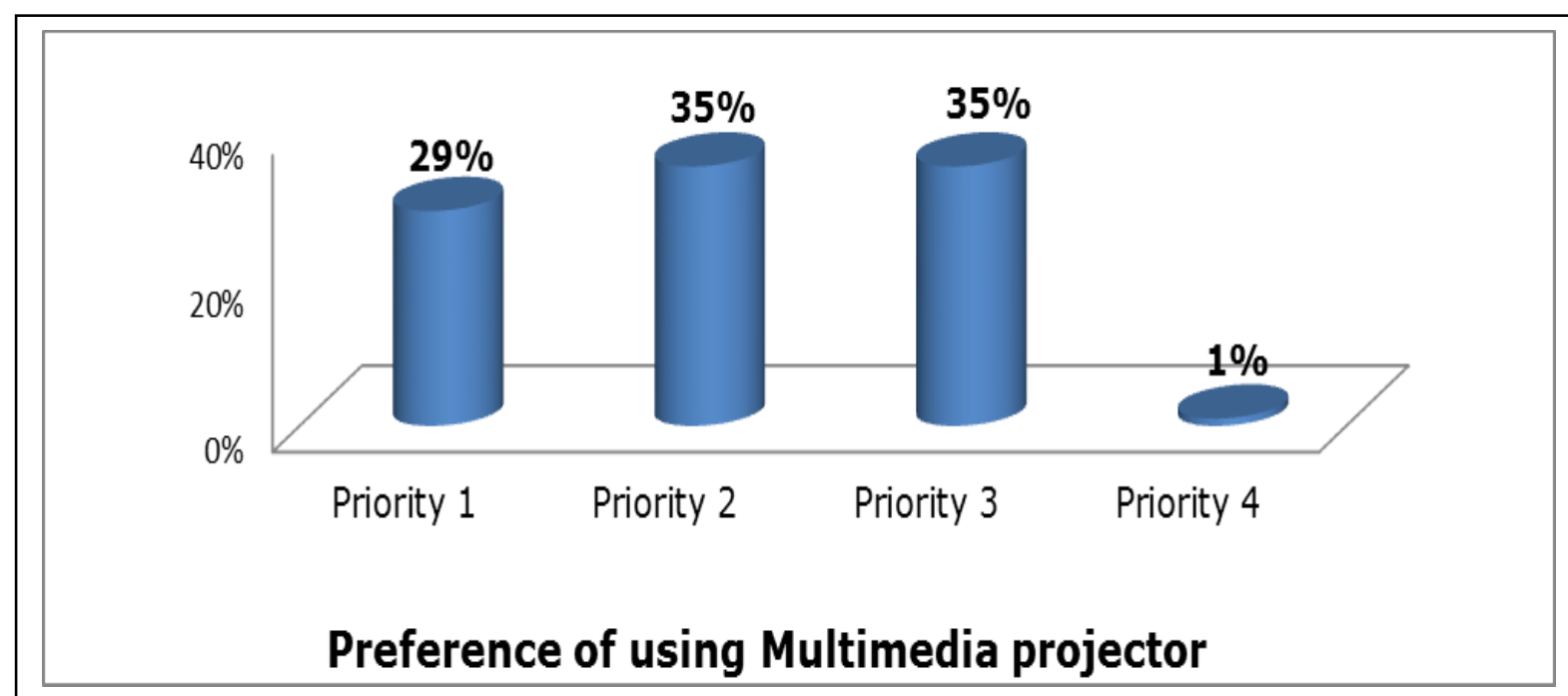




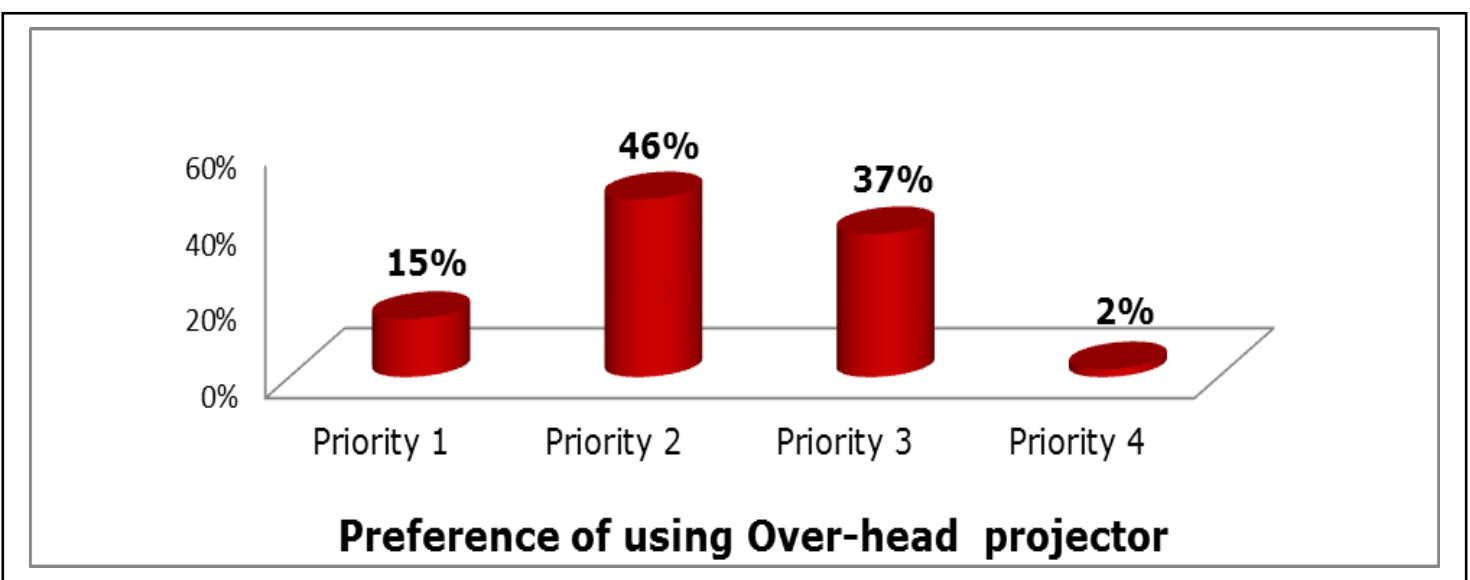

There are several teaching methods in the world that a teacher can use in the classroom, such us Dunn and Dunn focused on identifying relevant stimuli that may influence learning and manipulating the teaching environment, at about the same time as Joseph Renzulli recommended varying teaching strategies. Howard Gardner indentified individual talents or aptitudes in his Multiple Intelligences theories. Based on the works of Jung, the Myers-Briggs Type and Keirsey Temperament Sorter focused on understanding how people's personality affects the way they interact personally, and how this affects the way individuals respond to each other within the learning environment. Thework of Kolb and Anthony Gregorc's Type Delinetor follows a similar but more simplified approach. It is currently fashionable to divide education into different learning 'modes'.

Actually, all the effective teaching methods try to cover three modalities so that different students have equal opportunities to learn in a way that is effective for them. The three modalities are :

Visual :_Learning based on observation and seeing what is being learned.

Auditory : Learning based on listening to instructions/information.

Kinesthetic: Learning based on hands-on work and engaging in activities.

Amongst various methods, two are highlighted in this paper which I think most suitable and effective for education system in Bangladesh.

\subsection{Co-operative Learning Techniques:}

Cooperative learning techniques can be loosely categorized by the skill that each enhances (Barkley, Cross and Major, 2005), although it is important to recognize that many cooperative learning exercises can be developed to fit within multiple categories. Categories include: discussion, reciprocal teaching, graphic organizers, writing and problem solving. Each category includes a number of potential structures to guide the development of a cooperative learning exercise.

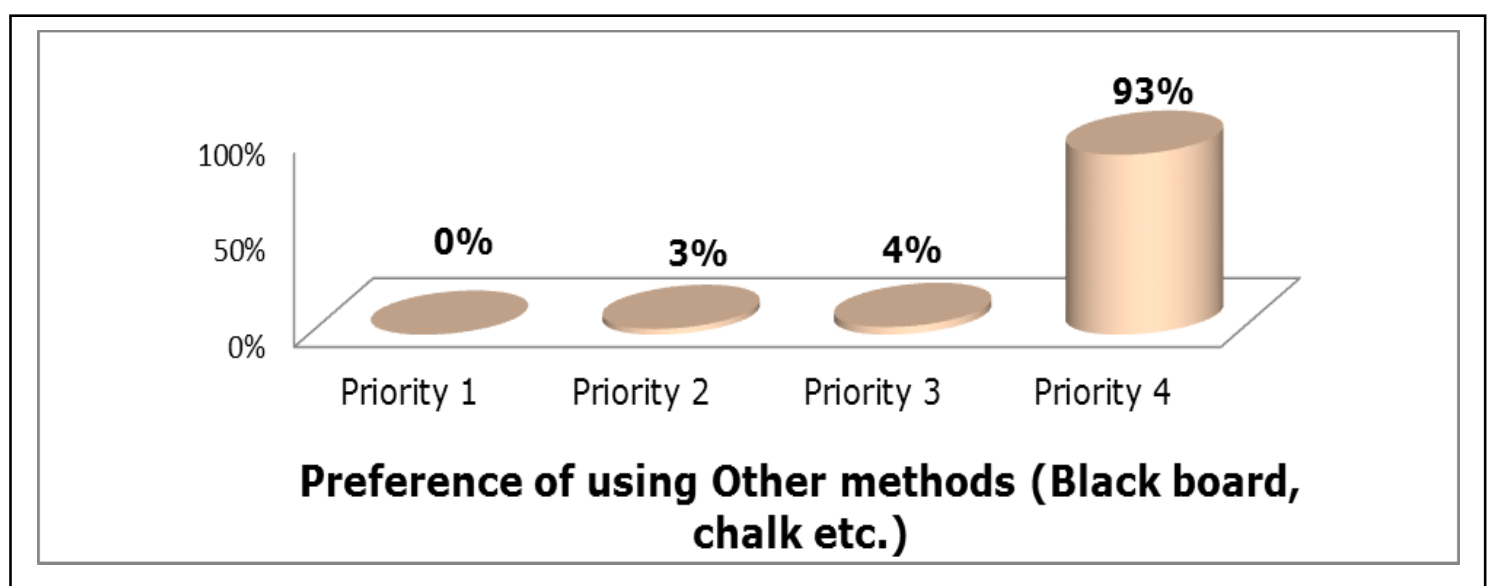

\subsubsection{Discussion:}

"A good give-and-take discussion can produce unmatched learning experiences as students articulate their ideas, respond to their classmates' points, and develop skills in evaluating the evidence of their own and others' positions." (Davis, 1993, p. 63)

Think-pair-share: As probably the best known cooperative learning exercise, the think-pair-share structure provides students with the opportunity to reflect on the question posed and then practice sharing and receiving 
potential solutions. Its simplicity provides instructors with an easy entry into cooperative learning and it is readily adaptable to a wide range of course constructs. (Example: Where Do I Begin? Using Think-Pair-Share to Initiate the Problem Solving Process)

Three-step interview: Students are first paired and take turns interviewing each other using a series of questions provided by the instructor. Pairs then match up and students introduce their original partner. At the end of the exercise, all four students have had their position or viewpoints on an issue heard, digested, and described by their peers.

\subsubsection{Reciprocal teaching:}

Slavin (1996), in a review of hundreds of studies, concluded that "students who give each other elaborated explanations (and less consistently, those who receive such explanations) are the students who learn most in cooperative learning." (p. 53)

Note-taking pairs: Poor note-taking leads to poor performance. Designing an exercise which requires students to summarize their understanding of a concept based on notes taken (with directed questions such as what is the definition of a concept, how is it used, what are the three most important characteristics of a topic) and receiving reflective feedback from their partner provides students the opportunity to find critical gaps in their written records.

Jigsaw: For more complex problems, this structure provides students the opportunity to develop expertise in one of many components of a problem by first participating in a group solely focused on a single component. In the second stage of the exercise, groups are reformed with a representative from each expert group who together now have sufficient expertise to tackle the whole problem.

\subsubsection{Graphic organizers: (discovering patterns and relationships)}

"Graphic organizers are powerful tools for converting complex information in to meaningful displays...They can provide a framework for gathering and sorting ideas for discussion, writing, and research." (Barkley, Cross and Major, 2005, p.205) See also, concept mapping.

Group grid: Students practice organizing and classifying information in a table. A more complex version of this structure requires students to first identify the classification scheme that will be used.

Sequence chains: The goal of this exercise is to provide a visual representation of a series of events, actions, roles, or decisions. Students can be provided with the items to be organized or asked to first generate these based on a predetermined end goal. This structure can be made more complex by having students also identify and describe the links between each of the sequenced components.

\subsubsection{Writing:}

Dyadic essays: Students prepare for the in-class portion of this exercise by developing an essay question and model answer based on assigned reading. Students typically need to be guided to develop questions that integrate material across classes as opposed to ones that simply recite facts presented in the reading. In class, students exchange essay questions and write a spontaneous answer essay. Students then pair up, compare and contrast the model answer and the spontaneously generated answer. Subsequently, questions and answers can be shared with the larger class.

Peer editing: As opposed to the editing process that often appears only at the final stage of a paper, peer editing pairs up students at the idea generation stage and peers provide feedback throughout the process. For example, the relationship begins as each student in the pair describes their topic ideas and outlines the structure of their work while their partner asks questions, and develops an outline based on what is described.

\subsubsection{Problem solving:}

Developing strategies and analysis Research by mathematics educators Vidakovic (1997) and Vidakovic and Martin (2004) shows that groups are able to solve problems more accurately than individuals working alone.

Send-a-problem: Students participate in a series of problem solving rounds, contributing their independently generated solution to those that have been developed by other groups. After a number of rounds, students are asked to review the solutions developed by their peers, evaluate the answers and develop a final solution. (Example: Understanding the Impact of (Fiscal and Monetary) Policy)

Three-stay, one-stray: Even students working in groups can benefit from the feedback of additional peers. In this structure, students periodically take a break from their work (often at key decision making points) and send one group member to another group to describe their progress. The role of the group is to gain information and alternative perspectives by listening and sharing. The number of times the group sends a representative to another group depends on the level of complexity of the problem. This method can also be used to report out final solutions. 


\subsection{Presentation, assignment, Seminars, workshop and conference:}

A presentation involves motivating listeners to accept a new idea, alter an existing opinion or act on a given premise. Students first thoroughly understand the topic before giving presentation. It increases confidence among students. In my survey, $41 \%$ students prefer single presentation, assignment and 59\% students prefer group presentation and assignment.

A teacher should encourage students to attend seminar, workshop and conference. Seminars motivate and make students active in learning. Workshop and conference give chance to meet other people of same profession.

It is very important for every student to get some practical knowledge. Moreover, all the universities should arrange some extra curriculum activities such as computer programming, debate, sports, etc. By doing these, students think beyond their knowledge and creative thinking is encouraged. In my survey, a good number of students (98\%) want practical exposure besides theoretical classes and $96 \%$ students prefer extra curriculum activities in university education. Again, $48 \%$ students are in favor of spot quiz. Teachers should take tutorial examination or quiz while delivering lectures. After the quiz, teachers correct their mistakes.
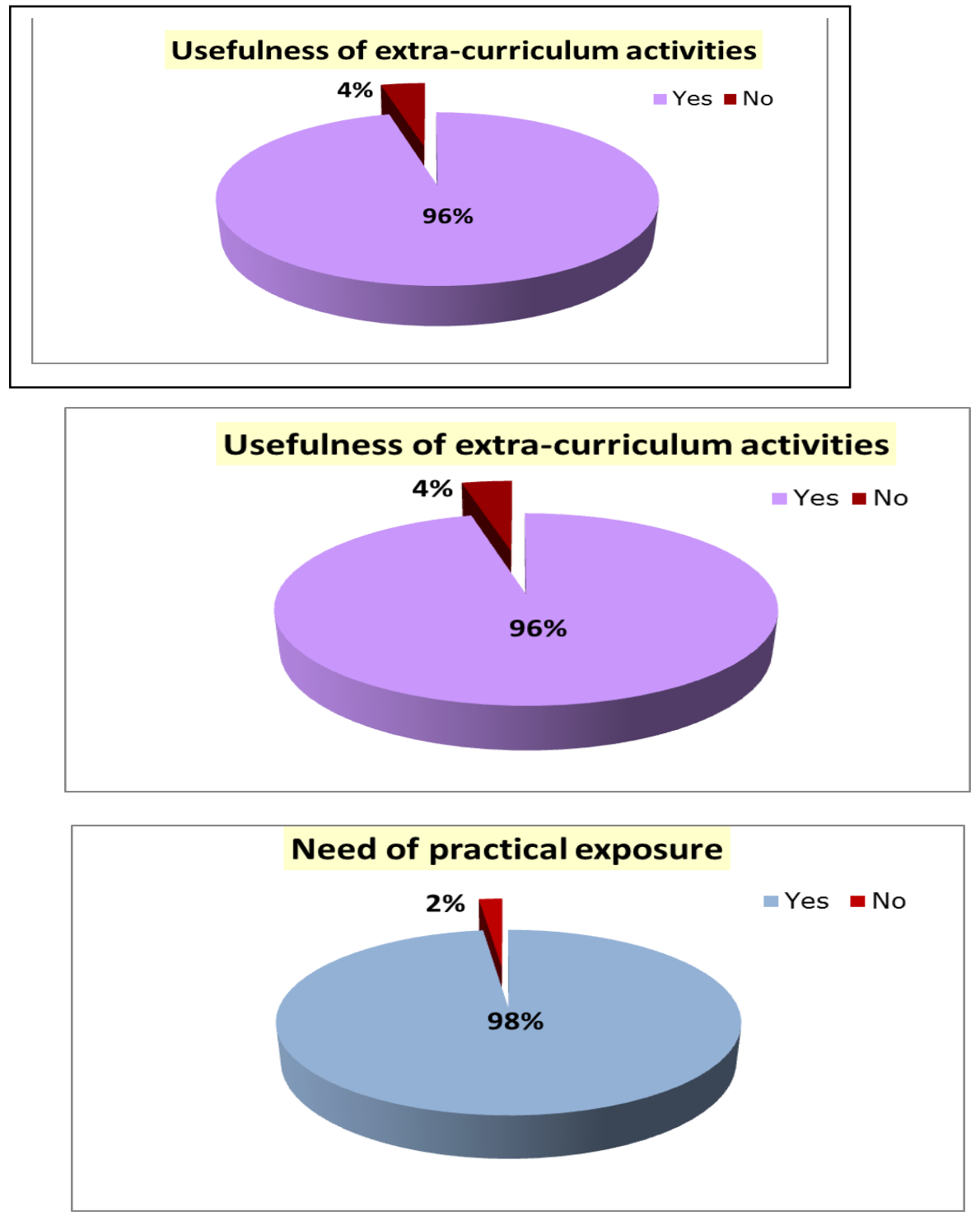

IV. My Experience

For the last two years I have been working in Daffodil International University (DIU) as a lecturer. We know that one of the most substantial uses in education is use of technology. DIU is one of the few universities in Bangladesh where all are using advanced modern technologies in learning system as well as in administrative purpose. DIU believes that technology is increasingly influential factor in education. Technology offers powerful learning tools that demand new skills and understandings of students including Multimedia and provides new ways to engage students, such as Virtual learning environments. In DIU, all the classrooms are 
installed with multimedia projectors. The use of technologies such as multimedia, power point and interactive whiteboard is capturing the attention of the students in the classroom. Technology is being used more not only in administrative duties but also instructing students. DIU is expanding its digital or e-service step by step.

Classroom Interactive Feedback System on website is very common for developed countries where any student can easily get lectures or reference book and interact with the teachers. But in Bangladeshi education system, it is a new concept of delivery lecture. Many public and private universities do not know about this teachinglearning method clearly. I feel very proud to say that all the teachers and students of DIU are using it and it is already proved to be very effective. From my survey, 93\% students say that DIU-learning Feedback System is necessary in present condition of education. Moreover,70\% of students say that DIU forum is also helpful for them to increase their knowledge.
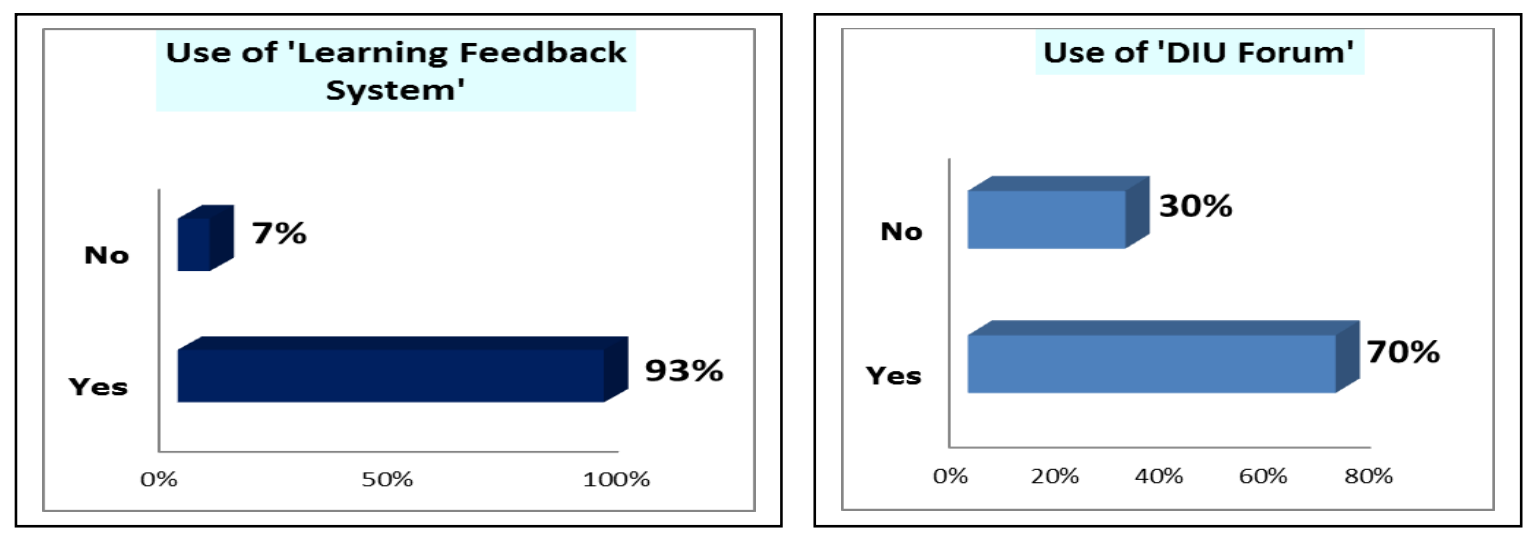

Again, if DIU students do not understand any questions while listening the lectures in the classroom, then they can ask about it without hesitation as classroom environment remains very friendly. From the survey report, 59\% of DIU students do not feel hesitates to ask questions in the classroom if they do not understand properly.

In DIU, while delivering lectures in the classroom, if any teacher feels that practical exposure or a ground visit is essential, then they can make necessary arrangements with the help of authority without facing any problem as the authority is very helpful. Here teachers are doing counseling and always take special care of weak students. For these reasons of ensuring the real quality of education, the enrollment of students in DIU is increasing day by day and students are coming from different countries of the world.

\section{Conclusion"}

In the last few decades, the demand for tertiary education in Bangladesh has increased tremendously. World Bank's recent interest in our tertiary education sector indicates its appreciation of this reality and possibility of additional resources mobilization in this sub-sector. Better understanding among teachers and students, introduction of modern teaching methods in the classroom and dedication of teachers and students can bring discipline. The teaching-learning situation in Bangladesh presents a lot of scope for education researchers and education developers. We have to develop our teaching-learning methodology not only for the development of the quality of the education and technology, but also to make university education in Bangladesh a 'brand' for others to follow. The aim of the tertiary education should be to make knowledgeable and good human being, not to give a degree after a given time periods.

\section{References}

[1]. Dabbagh, N. (2005). Pedagogical models for E-Learning: A theory-based design framework.

[2]. International Journal of Technology in Teaching and Learning, 1(1), 25-44.

[3]. Dabbagh, N., \& Kitsantas, A. (2009). Exploring how experienced online instructors use integrativelearning technologies to support self-regulated learning. International Journal of Technology in Teaching and Learning, 5(2), 154-168.

[4]. Daniel, S.K. (2004). Conception and Implementation of Rich Pedagogical Scenarios through Collaborative portal sites, in Mario Tokoro and Luc Steels (eds.) The Future of Learning II, Sharing representations and Flow in Collaborative Learning Environments, IOS Press, 2004.

[5]. Deden, A (2005). Program packaging and e-support for online student retention. Retrieved from http://:www.odlaa.org/events/2005conf/nonref/odlaa2005Deden.pdf

[6]. Hathaway, D.M. (2009). Assessing quality dimensions and elements of online learning enacted in a higher education setting. $\mathrm{PhD}$ dissertation, George Mason University. Retrieved from http://digilib.gmu.edu:8080/bitstream/1920/4593/1/Hathaway_Dawn.pdf

[7]. Jara, M., \& Mohamad, F. (2007). Pedagogical templates for e-learning. Occasional papers in Workbased learning 2, Institute of Education, University of London. Internet 8 November 2007: Retrieved from http://www.wlecentre.ac.uk/cms/files/occasionalpapers/wle_op2.pdf 